\title{
Terlipressin in septic shock: what do we know?
}

\author{
Zi-Meng Liu, Xiang-Dong Guan \\ Department of Critical Care Medicine, The First Affiliated Hospital, Sun Yat-sen University, Guangzhou 510080, China \\ Correspondence to: Xiang-Dong Guan, PhD, MD. Department of Critical Care Medicine, The First Affiliated Hospital, Sun Yat-sen University, 58 \\ Zhongshan 2nd Road, Guangzhou 510080, China. Email: guanxiangdong1962@163.com. \\ Provenance and Peer Review: This article was commissioned and reviewed by the Section Editor Xue-Zhong Xing [National Cancer Center (NCC)/ \\ Cancer Hospital, Chinese Academy of Medical Sciences (CAMS) and Peking Union Medical College (PUMC), Beijing, China]. \\ Response to: Williams MD, Russell JA. Terlipressin or norepinephrine in septic shock: do we have the answer? J Thorac Dis 2019;11:S1270-3. \\ Rocha DL, Moreira FT, Serpa Neto A. Terlipressin as a first choice in septic shock-not yet. J Thorac Dis 2019;11:S1384-6.
}

Submitted Dec 13, 2019. Accepted for publication Feb 13, 2020.

doi: $10.21037 /$ jtd.2020.02.40

View this article at: http://dx.doi.org/10.21037/jtd.2020.02.40

Despite the significant progress of the understanding and resuscitation strategy, morbidity and mortality of septic shock remains high (1). To restore the tissue perfusion in septic shock, norepinephrine (NE) is most common and the first-line recommended vasoconstrictor (2). However, in cases with severe refractory septic shock, high doses NE may result in myocardial injury and alter the sepsisassociated immunomodulation (3). Concerning about the negative effects of high dose norepinephrine therapy in septic shock, vasopressin with the different receptor mechanisms has been suggested. The vasoconstriction of vasopressin is via vasopressin $\mathrm{V} 1$ receptor activation. However, it was now demonstrated that vasopressin may cause other negative side effects via activation of other receptors. Activation of $\mathrm{V} 2$ receptors on the renal collecting ducts might induced antidiuretic effect. Activation of V2 receptors on endothelial cells might lead to Von Willebrand factor release. V3 receptors activation in the pituitary gland increased ACTH secretion. Oxytocin receptors on vascular endothelial cells might increase nitric oxide synthase activity which might cause vasodilation) (4). Terlipressin, which is a synthetic vasopressin analogue has a greater selective affinity to the $\mathrm{V} 1$ receptor. Therefore terlipressin might be an optimal alternative to vasopressin. Our study of continuous terlipressin infusion in patients with septic shock is the largest randomized, controlled, double-blind multicentre study conducted so far (5). There were several major limitations in our trial which had been mentioned in our publication. Our trial provided some useful clinical evidences of terlipressin in septic shock. But we did not find continuous administration of terlipressin compared to NE in patients with septic shock could decrease 28-day mortality. Terlipressin was effective in restoring arterial hypotension in septic shock. Both norepinephrine and terlipressin improved the SOFA scores on day 7 after randomization (5). As the comments from Rocha et al. (6), our analysis did not provide sufficient evidences to recommend terlipressin superior to NE as the first line vasopressor in septic shock. Terlipressin might be served as an important alternation in refractory shock now. Thomas and his colleagues reported a web based survey on the use of vasoactive drugs in septic shock which was endorsed by the European Society of Intensive Care Medicine (ESICM) (7). The experts in the survey recommended vasopressin or terlipressin as second vasopressor ("GOOD" degree of consensus and "STRONG" Grade of recommendation) (7).

The reasonable dosage of terlipressin in septic shock was still unknown. In patients with liver cirrhosis and septic shock the maximum dosage of terlipressin was $312 \mu \mathrm{g} / \mathrm{h}$ with the overall rate of adverse events was $41 \%$ with $29 \%$ experiencing "peripheral cyanosis" (8). The maximum dosage of continuous terlipressin infusion was $160 \mu \mathrm{g}$ per hour in our study which was relative lower than that in liver cirrhosis. However the serious adverse events in terlipressin group was still up to $30 \%$ (5). In light of the serious adverse events, we recommended the maximum terlipressin infusion rate in septic shock should not exceed $160 \mu \mathrm{g} / \mathrm{h}$.

According to the SSC guidelines (2), adequate fluid resuscitation is one of the important initial therapies of septic shock. So far, however, there is no standard protocol 
of fluid resuscitation during septic shock treatment. Therefore, based on our protocol, the doctors administered fluid treatments following the clinical guidelines and patient's conditions. The similar protocols of fluid resuscitation had been applied in several famous studies (9). Therefore, we did not record and compare the use of resuscitation fluids in this trial. But we have provided some information of fluid infusion in the appendix (5).

The 28-day mortality of septic shock reported in our study was $39-40 \%$ which was questioned to be too high (5). So far, however, the reported mortality rates of septic shock were different among various studies. Some recent studies showed that the mortality of septic shock remained 40-60\% (10,11). Moreover, two studies in China also showed that the mortality of septic shock in ICU was $43.5 \%$ to $46.6 \%(12,13)$. We agreed with Professor James A. Russell about the validity of using a short term (28-day) mortality as the endpoint of our analysis (14). During resuscitation of shock, the tissue perfusion, oxygen delivery or the recovery of organ dysfunction might be the more reasonable outcomes in the clinic.

There were some evidences supported vasopressin or terlipressin might have advantages in organ protection. A few small clinical studies showed a renal protective effect of terlipressin $(15,16)$. Meanwhile, our trial found the reduction in serum creatinine on D5 and D7 was more significant in the terlipressin group (Data shown in the appendix) (5). Recently Gary Duclos reported that low dose terlipressin combined with norepinephrine in septic shock patients with $\mathrm{ScvO}_{2}$ above $70 \%$ was associated with a more rapid recovery of organ dysfunction (17). In the VANISH trial the early use of vasopressin decreased the need of renal replacement therapy (9). Although all the findings on organ protection should be interpreted cautiously, they also deserved our attention.

In summary, not sufficient evidences proved terlipressin to be the first line vasopressor in septic shock. Terlipressin could be one of the alternations in patients with refractory septic shock. The organ protection of vasopressin or terlipressin need to be further investigated. Considering the high rate of serious adverse events, the terlipressin infusion rate should be strictly monitored in patients with septic shock.

\section{Acknowledgments}

We would like to thank all of the doctors, nurses, technicians, and patients involved at the participating centres for their dedication to the study (5). Funding: None.

\section{Footnote}

Conflicts of Interest: All authors have completed the ICMJE uniform disclosure form (available at http://dx.doi. org/10.21037/jtd.2020.02.40). The authors have no conflicts of interest to declare.

Ethical Statement: The authors are accountable for all aspects of the work in ensuring that questions related to the accuracy or integrity of any part of the work are appropriately investigated and resolved.

Open Access Statement: This is an Open Access article distributed in accordance with the Creative Commons Attribution-NonCommercial-NoDerivs 4.0 International License (CC BY-NC-ND 4.0), which permits the noncommercial replication and distribution of the article with the strict proviso that no changes or edits are made and the original work is properly cited (including links to both the formal publication through the relevant DOI and the license). See: https://creativecommons.org/licenses/by-nc-nd/4.0/.

\section{References}

1. Singer M, Deutschman CS, Seymour CW, et al. The Third International Consensus Definitions for Sepsis and Septic Shock (Sepsis-3). JAMA 2016;315:801-10.

2. Rhodes A, Evans LE, Alhazzani W, et al. Surviving Sepsis Campaign: International Guidelines for Management of Sepsis and Septic Shock: 2016. Intensive Care Med 2017;43:304-77.

3. Müllner M, Urbanek B, Havel C, et al. Vasopressors for shock. Cochrane Database Syst Rev 2004;(3):CD003709.

4. Mårtensson J, Gordon AC. Terlipressin or norepinephrine, or both in septic shock? Intensive Care Med 2018;44:1964-6.

5. Liu ZM, Chen J, Kou Q, et al. Terlipressin versus norepinephrine as infusion in patients with septic shock: a multicentre, randomised, double blinded trial. Intensive Care Med 2018;44:1816-25.

6. Rocha DL, Moreira FT, Serpa Neto A. Terlipressin as a first choice in septic shock-not yet. J Thorac Dis 2019;11:S1384-6.

7. Scheeren TWL, Bakker J, De Backer D, et al. Current use of vasopressors in septic shock Ann Intensive Care 2019 
30;9:20.

8. Choudhury A, Kedarisetty CK, Vashishtha C, et al. A randomized trial comparing terlipressin and noradrenaline in patients with cirrhosis and septic shock. Liver Int 2017;37:552-61.

9. Gordon AC, Mason AJ, Thirunavukkarasu N, et al. Effect of Early Vasopressin vs Norepinephrine on Kidney Failure in Patients With Septic Shock: The VANISH Randomized Clinical Trial. JAMA 2016;316:509-18.

10. Sadaka F, O'Brien J, Migneron M, et al. Activated protein $\mathrm{C}$ in septic shock: a propensity-matched analysis. Crit Care 2011;15:R89.

11. SepNet Critical Care Trials Group. Incidence of severe sepsis and septic shock in German intensive care units: the prospective, multicentre INSEP study. Intensive Care Med 2016;42:1980-9.

12. Lin J, Liu P, Zhuang H, Duan M, Li A. The clinical analysis of 419 severe sepsis patients in intensive care unit.

Cite this article as: Liu ZM, Guan XD. Terlipressin in septic shock: what do we know? J Thorac Dis 2020;12(4):1632-1634. doi: $10.21037 /$ jtd. 2020.02 .40
Zhonghua Wei Zhong Bing Ji Jiu Yi Xue 2014;26:171-4.

13. Han XD, Sun H, Huang XY, et al. A clinical study of pituitrin versus norepinephrine in the treatment of patients with septic shock. Zhongguo Wei Zhong Bing Ji Jiu Yi Xue 2012;24:33-7.

14. Williams MD, Russell JA. Terlipressin or norepinephrine in septic shock: do we have the answer? J Thorac Dis 2019;11:S1270-3.

15. Albanèse J, Leone $M$, Delmas A, et al. Terlipressin or norepinephrine in hyperdynamic septic shock: a prospective, randomized study. Crit Care Med 2005;33:1897-902.

16. Xiao X, Zhang J, Wang Y, et al. Effects of terlipressin on patients with sepsis via improving tissue blood flow. J Surg Res 2016;200:274-82.

17. Duclos G, Cantaloube M, Medam S, et al. Preliminary results of synergy between norepinephrine and terlipressin during septic shock. Intensive Care Med 2019;45:730-2. 